\title{
Influence of Poly(Ethylene Grycol) - (PEG) on the Properties of Influence of Poly(3-Hydroxybutyrate-CO-3- Hydroxyvalerate) - PHBV
}

\author{
Sara E. M. Catoni, Ketlyn N. Trindade, Caio A. T. Gomes, Andréa L. S. Schneider, Ana P. T. Pezzin \\ Universidade da Região de Joinville, UNIVILLE
}

Valdir Soldi

Universidade Federal de Santa Catarina, UFSC

\begin{abstract}
Films of poly(3-hydroxybutyrate-co-3-hydroxyvalerate) - PHBV with polyethylene glycol (PEG) were prepared by casting solvent evaporation. The thermal behavior, morphology, crystallinity and molecular weight of these films were studied by the following techniques: differential scanning calorimetry (DSC), scanning electron microscopy (SEM), X-ray diffraction (XRD), size exclusion chromatography (SEC). Mixtures of PHBV/PEG showed a high crystallinity degree, measured by XRD, with values ranging between 60 and $90 \%$ according to the concentration of PEG. The melting temperature of PHBV decreased with increasing addition of plasticizer (PEG) in the mixture. SEM results showed that the mixtures were uniform, except for the composition 50/50 which proved to be heterogeneous, as evidenced by the presence of two phases. PHBV had molar mass $\left(\mathrm{Mw}=206000 \mathrm{~g} \mathrm{~mol}^{-1}\right)$, while the introduced PEG molar mass $\left(\mathrm{Mw}=1350\right.$ to $\left.1650 \mathrm{~g} \mathrm{~mol}^{-1}\right)$. The addition of PEG caused the crystallinity of the polymer films to increase owing to the high crystallinity of PEG. The melting point of the PHBV/PEG mixtures also diminished. In addition, SEC analysis of the blends indicated a reduced molar mass for the mixtures in comparison to pure PHBV (100/0).
\end{abstract}

Keywords: Characterization, PEG, $P H B V$.

\section{Introduction}

The polyhydroxyalkanoates (PHAs) are natural substances accumulated inside the cells as a reserve carbon and energy under particular conditions of growth $^{[1]}$.

There is a significant interest in the study of PHAs due to its commercial value as biodegradable thermoplastic being a potential alternative to replace the use of plastics derived from petroleum. Poly(3-hydroxybutyrate) $\mathrm{P}(3 \mathrm{HB})$ is the best characterized PHA and many bacteria are able to synthesize it, however, this biopolymer has no industrial properties interesting (hard and brittle). The incorporation of 3-hydroxyvalerate $(3 \mathrm{HV})$ in the production of the copolymer poly(3-hydroxybutyrateco-3-hydroxyvalerate) - PHBV, results in the formation of a polymer with the most interesting features of the industrial point of view ${ }^{[2]}$.

While $\mathrm{P}(3 \mathrm{HB})$ homopolymer has a melting temperature $\left(\mathrm{T}_{\mathrm{m}}\right)$ around $173-180{ }^{\circ} \mathrm{C}$ and a glass transition temperature $\left(\mathrm{T}_{\mathrm{g}}\right)$ of about -5 to $5{ }^{\circ} \mathrm{C}$, the addition of $3 \mathrm{HV}$, reduces the melting temperature of crystals, the module and tensile strength and at the same time increases flexibility, impact resistance and ductility. With the increase of $3 \mathrm{HV}$, the melting temperature decreases ranging from 75 to $170{ }^{\circ} \mathrm{C}$ depending on the percentage of $3 \mathrm{HV}$ in the copolymer. This is particularly beneficial, because with the decrease in melting temperature, the copolymer can be processed at lower temperatures, reducing significantly the thermal degradation. The crystallinity degree of PHBV is around $39-69 \%$ depending on the percentage of the respective monomers. The high percentage of $3 \mathrm{HV}$ decreases the crystallinity making the polymer more flexible ${ }^{[3]}$.

The PHAs are thermoplastic biocompatible, nontoxic, biodegradable and can be produced from renewable sources. They have a high degree of polymerization are highly crystalline, optically active, isotactic and insoluble in water ${ }^{[4]}$. Due to their biocompatibility, the PHAs can be used in controlled release of drugs, hormones, insecticides and herbicides.

In general, matrices consisting of PHAs have a high crystallinity degree, justifying its slow degradation, making the attack of enzymes more difficult. Thus, the surface modification with hydrophilic polymers such as PEG has been explored in order to obtain particles that escape from capture and recognition by phagocytic cells after in vivo administration, staying for a longer timer in the systemic circulation ${ }^{[5]}$.

PEG has outstanding properties, including good solubility in water and in organic solvents, a lack of toxicity, and no antigenicity, and, consequently, no immunogenicity, all of which are essential properties for drug formulations. In addition, PEG is hydrophilic and not biodegradable.

PEG has been commonly applied in a wide range of human intravenous formulations and veterinary pharmaceuticals and so far has been considered as immunologically safe, being eliminated from the body intact by the kidneys. More recently, PEG has been identified as a therapeutic agent to have a variety of experimental settings and veterinary therapy ${ }^{[6]}$.

Corresponding author: Ana P. T. Pezzin, Laboratório de Materiais, Universidade da Região de Joinville - UNIVILLE, Rua Paulo Malschitzki, 10, Campus Universitário, Zona Industrial, CEP 89219-719, Joinville, SC, Brazil, e-mail: anapezzin@yahoo.com.br 

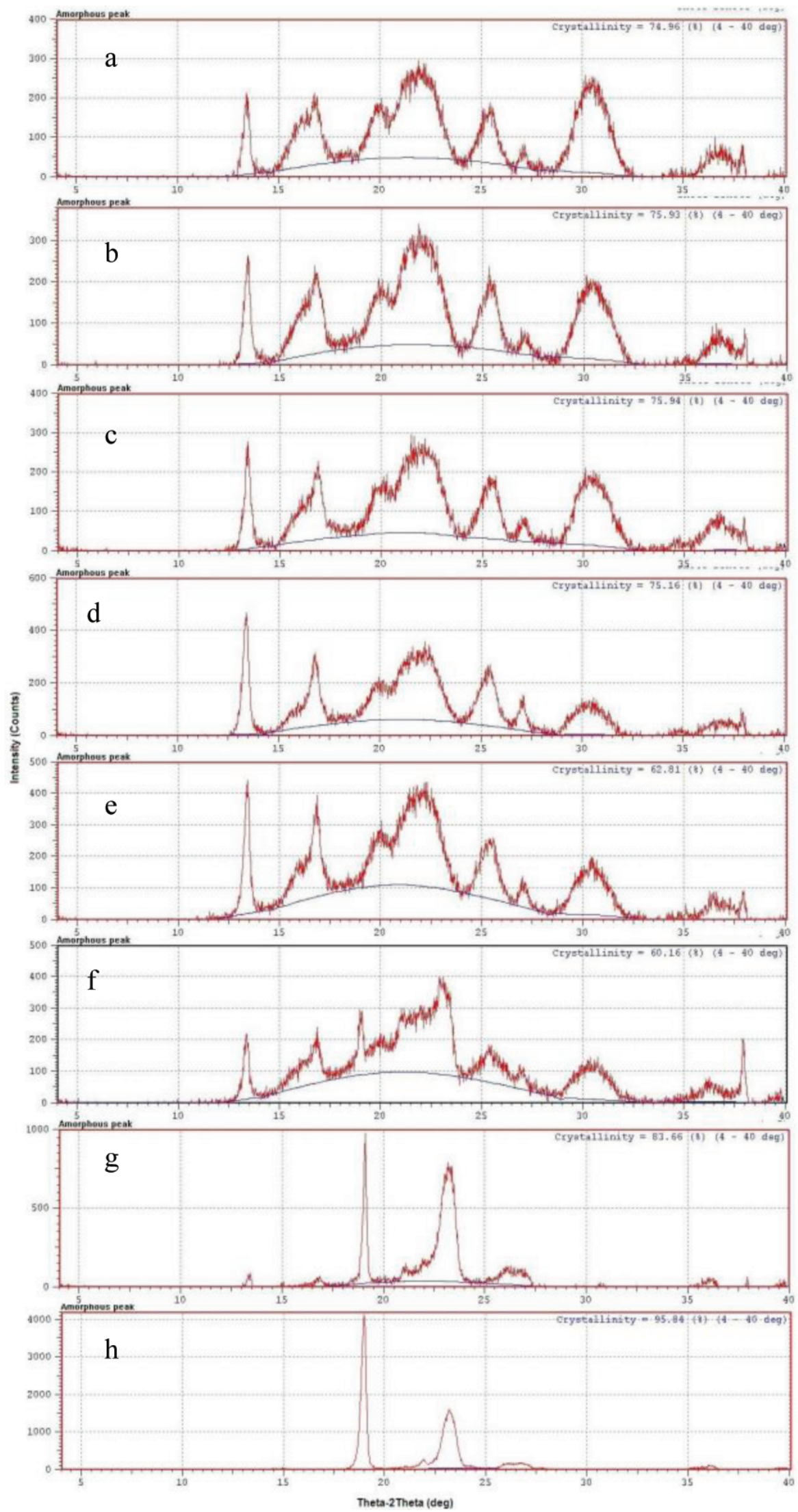

Figure 1. X-ray diffractions of the PHBV/PEG mixtures: a) 100/0, b) 98/02, c) 95/05, d) 90/10, e) 80/20, f) 50/50, g) 20/80 e h) 0/100. 
In order to obtain a new material with better properties PHBV/PEG mixtures in different proportions prepared by casting were characterized by XRD, SEM, DSC and SEC.

\section{Experimental}

\section{Materials}

Poly(3-hydroxybutyrate-co-3-hydroxyvalerate)PHBV was provided by PHB Industrial - SP $\left(\mathrm{M}_{\mathrm{W}}=207000\right.$ with $\left.3.6 \% 3 \mathrm{HV}\right)$. Polyethylenoglycol - PEG $\left(\mathrm{M}_{\mathrm{W}}=1350\right.$ - 1650) was supplied by Cromato Chemicals Ltda.

\section{Films preparation}

Films of PHBV/PEG with weight ratios of 100/0, $98 / 02,95 / 05,90 / 10,80 / 20,20 / 80,50 / 50,20 / 80$ and $100 / 0$, were prepared by solvent casting. PHBV and PEG were dissolved separately in chloroform to form $5 \%$ $(\mathrm{w} / \mathrm{v})$ solutions. PHBV was dissolved in chloroform at $80{ }^{\circ} \mathrm{C}$ under constant agitation. PEG was also dissolved in chloroform, but at a temperature of $25{ }^{\circ} \mathrm{C}$ under agitation. The solutions with the different compositions

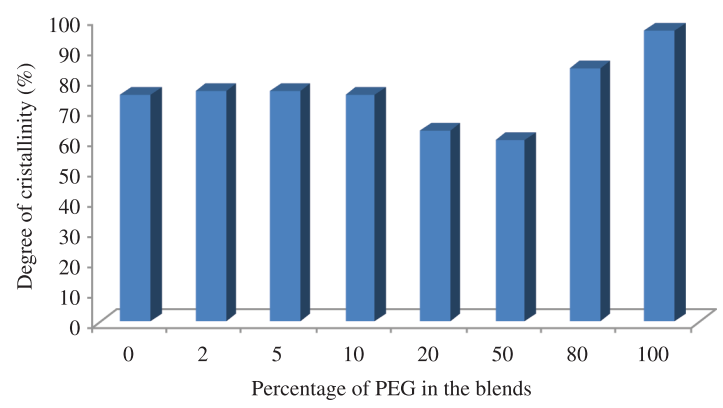

Figure 2. Influence of percentual of PEG in the crystallinity degree of PHBV/PEG mixtures. were made by mixing of the appropriate amounts of the separate solutions and after magnetic mixing for $2 \mathrm{~h}$ until completely homogenized at room temperature. The mixture was poured in a Petri dish with $10 \mathrm{~cm}$ in diameter and placed in an evaporator system with chloroformsaturated atmosphere for $96 \mathrm{~h}$. The films were dried in a vacuum oven at $30{ }^{\circ} \mathrm{C}$ for $24 \mathrm{~h}$ at $500 \mathrm{mmHg}$ to remove excess chloroform and stored in a desiccator.

\section{Films characterization}

PHBV/PEG mixtures were characterized by X-ray diffractometry (DRX), scanning electron microscopy (SEM), differential scanning calorimetry (DSC) and size exclusion chromatography (SEC).

DSC measurements were performed with a DSC of TA instruments. Samples of $5 \mathrm{mg}$ sealed in aluminum pans were heated from ambient temperature to $190{ }^{\circ} \mathrm{C}$ at heat rating of $10{ }^{\circ} \mathrm{C} \mathrm{min}^{-1}$. Subsequently, they were cooled to -90 at $20{ }^{\circ} \mathrm{C} \mathrm{min}^{-1}$. The second heating was recorded from -90 to $190{ }^{\circ} \mathrm{C}$ at $10{ }^{\circ} \mathrm{C} \mathrm{min}{ }^{-1}$.

The X-ray diffraction patterns of samples were obtained in a SHIMADZU, model XRD 6000 diffractometer. The radiation used was $\mathrm{CuK} \alpha$ in the angular range 4 to $40^{\circ}$. The wavelength used was $\lambda=1.54060$, voltage of $40.0 \mathrm{kV}$ and current of $30.0 \mathrm{~mA}$.

SEM was carried out to examine the phase morphology of the films. A scanning electron microscopy (Zeiss DSM 940A) operated at $20 \mathrm{kV}$ was used to observe the superior surface of samples, coated with a thin layer of gold by vacuum deposition using a Sputter Coater BAL-TEC SCD 050.

Molecular weights (weight-average molecular weight $-M_{w}$, number-average molecular weight $-M_{n}$; peak molecular weight - $M_{p}$ and polydispersity index - I $)$ were determined by SEC using an HPLC model D-7000IF (Merck Hitachi with refractive index detector RID 71) operating with chloroform as solvent and PS standards were used for calibration.

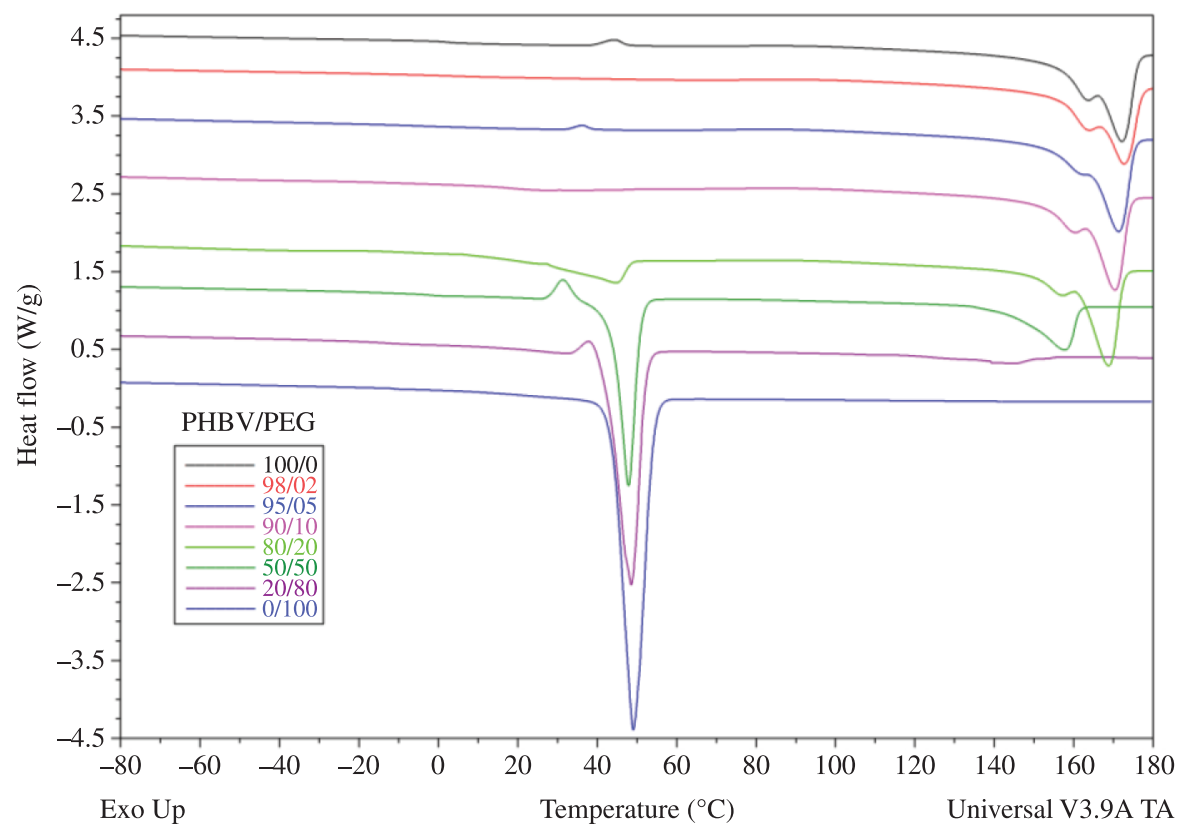

Figure 3. DSC curves for the PHBV/PEG mixtures (second heating). 


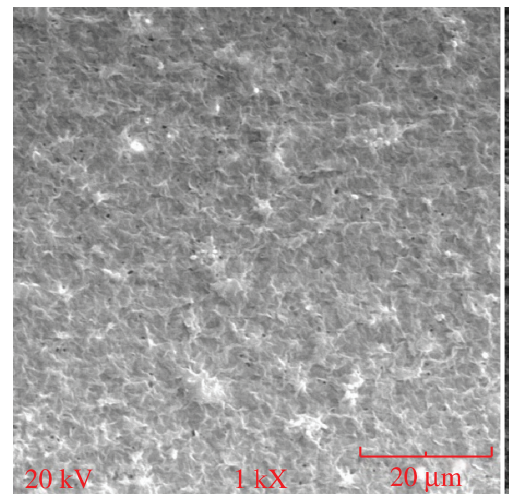

(a)

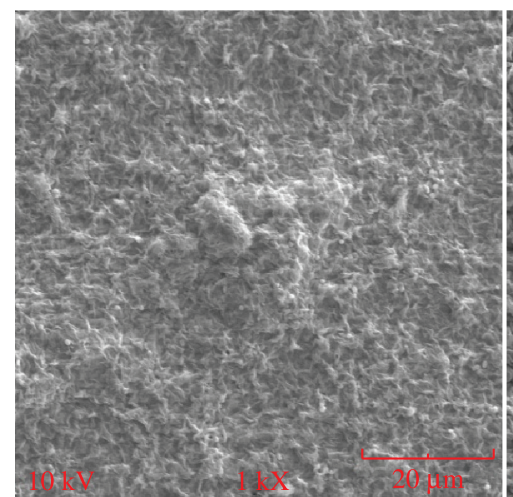

(c)

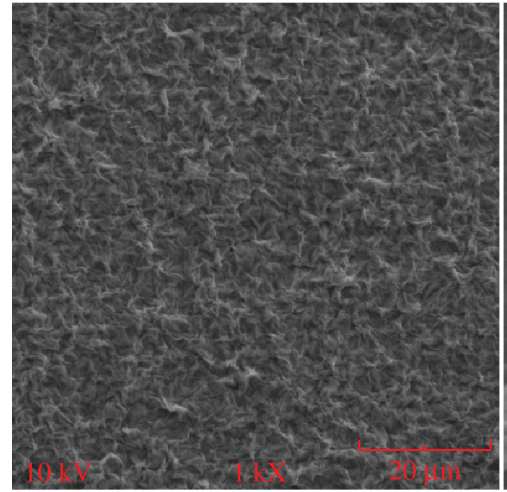

(e)

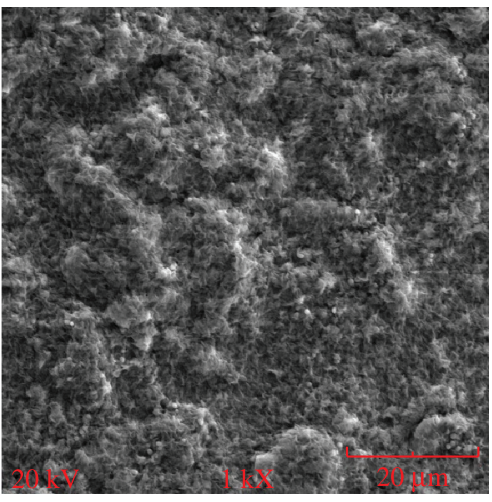

(b)

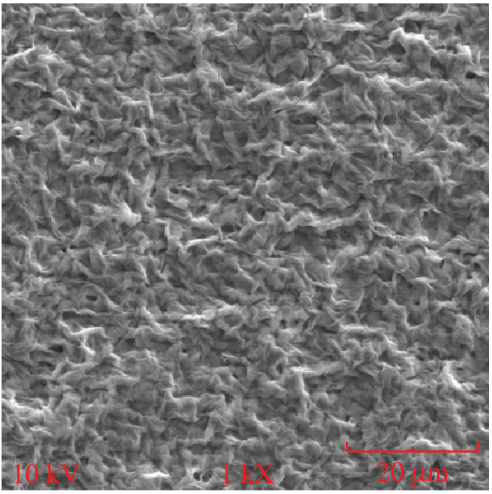

(d)

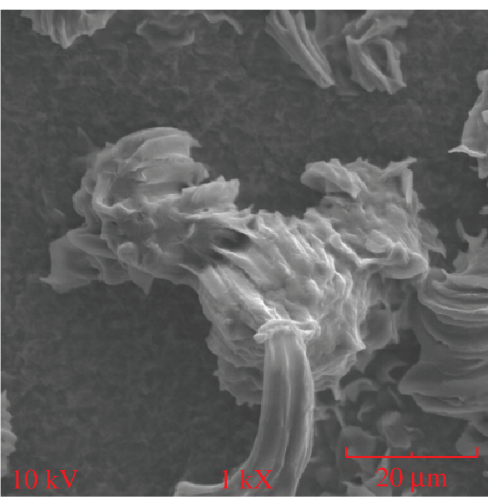

(f)

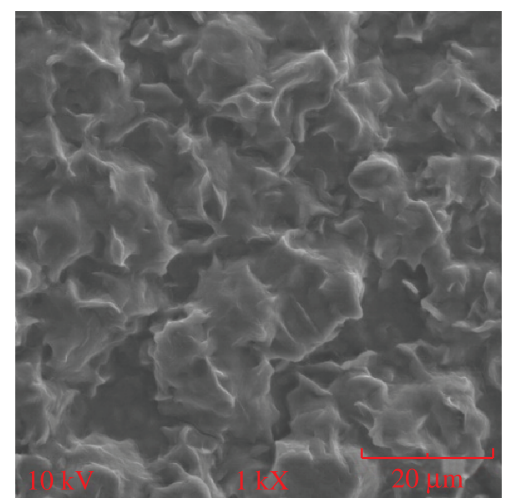

(g)

Figure 4. SEM of superior surface of the PHBV/PEG mixtures. 1000X: a) 100/0, b) 98/02, c) 95/05, d) 90/10, e) 80/20, f) 50/50, g) $20 / 80$. 


\section{Results and Discussion}

\section{$X$-ray diffractometry - DRX}

As it is observed in Figures 1 and 2 the crystallinity degree of the mixtures calculated by XRD varied from 60 to $90 \%$. Up to $10 \%$ of PEG in the mixture, the crystallinity of the polymer remained at around $75 \%$, similar to pure PHBV. Between 20 and 50\% of PEG in the mixture, it was notice a decrease in the crystallinity degree with values around $60 \%$. Adding $80 \%$ of PEG, the crystallinity increased to approximately $90 \%$. This profile can be explained due to high PEG crystallinity. The diffraction profile for the neat homopolymers and the mixtures is shown in Figure 2. As can be seen, the diffraction peaks appear at $2 \theta$ around 13.5, 16.9, 20, 22, 25.5, 27 and $30^{\circ}$ for the PHBV ${ }^{[4]}$ and PEG shows two main peaks at $2 \theta$ around $9.5^{\circ}$ and $11.5^{\circ}[7]$

\section{Differential scanning calorimetry - DSC}

DSC thermograms of the second heating scan for the PHBV/PEG mixtures are shown in Figure 3 and data obtained from DSC curves are shown in Table 1. The neat PHBV showed an endothermic peak corresponding to a melting temperature $\left(\mathrm{T}_{\mathrm{m}}\right)$ at $172.2^{\circ} \mathrm{C}$, a second peak at lower temperature $\left(163.2^{\circ} \mathrm{C}\right)$ and a glass transition temperature $\left(\mathrm{T}_{\mathrm{g}}\right)$ at $2.6^{\circ} \mathrm{C}$. The double melting peaks of PHBV were caused by melting, recrystallization and remelting during heating ${ }^{[8]}$. The $\mathrm{T}_{\mathrm{m}}$ of PHBV remained constant with the addition of up to $10 \%$ of PEG. For the sample with $20 \%$ of PEG the Tm of PHBV decreased by $3.4{ }^{\circ} \mathrm{C}$ from $172.2^{\circ} \mathrm{C}$ to $168.8^{\circ} \mathrm{C}$. With 50 and $80 \%$ of PEG, the Tm of PHBV decreased by $14.5^{\circ} \mathrm{C}$ and $27.2^{\circ} \mathrm{C}$, respectively.

The $\mathrm{T}_{\mathrm{m}}$ of the PHBV/PEG mixtures decreased as it was expected considering PEG addition, since it is used as a plasticizer. Usually, the plasticizers weakened the intermolecular forces between the adjacent polymer chains. Consequently, there was a change in free volume with reduction of the melting temperature $\left(\mathrm{T}_{\mathrm{m} 1} \text { and } \mathrm{T}_{\mathrm{m} 2}\right)^{[6]}$.

For PHBV the use of plasticizers has a similar effect to increasing molar concentration of $3 \mathrm{HV}$. The decrease in $\mathrm{T}_{\mathrm{g}}$ can be explained by the use of plasticizer (PEG), this occurs due to increased movement of the chains, because the plasticizer reduces the severity of intermolecular forces. Besides the plasticizer increases the impact strength and ductility at low temperatures ${ }^{[9]}$. However, the $\mathrm{T}_{\mathrm{g}}$ can not be determined due to high crystallinity of the polymers.

\section{Scanning electron microscopy - SEM}

The phase morphology of the PHBV/PEG mixtures is shown in Figure 4. The melting temperature of PHBV has had a pronounced decrease with increasing concentration of PEG in the sample, indicating miscibility of polymers. The SEM micrographs of surface revealed that the PHBV morphology is distinct from the PEG morphology. For the mixtures with less than $20 \%$ of PEG we cannot distinguish the presence of two distinct phases, observing a very homogeneous morphology (Figures 4b-e), due to the low percentage of PEG in the samples. For the sample with high percentage of PEG the dominant morphology is more similar to the component that is in the highest percentage (PEG). However, for the sample 50/50 (Figure 4f), we can observe clearly two phases, due to the equivalent percentage of the components in the sample.

Table 1. Data of glass transition temperature $\left(\mathrm{T}_{\mathrm{g}}\right)$, melting temperature $\left(\mathrm{T}_{\mathrm{m}}\right)$, melting entaphy $\left(\Delta \mathrm{H}_{\mathrm{m}}\right)$ for the $\mathrm{P}(3 \mathrm{HB})$-co(3HV)/PEG mixtures obtained by DSC.

\begin{tabular}{|c|c|c|c|c|c|}
\hline $\begin{array}{c}\text { Sample } \\
\text { PHBV/PEG }\end{array}$ & $\begin{array}{l}\mathbf{T}_{\mathrm{g}} \\
\left({ }^{\circ} \mathbf{C}\right)\end{array}$ & $\begin{array}{l}\mathbf{T m}_{1} \\
\left({ }^{\circ} \mathbf{C}\right)\end{array}$ & $\begin{array}{c}* \Delta \mathbf{H}_{\mathrm{m} 1} \\
(\mathrm{~J} / \mathrm{g})\end{array}$ & $\begin{array}{l}\mathbf{T m} \\
\left({ }^{\circ} \mathbf{C}\right)\end{array}$ & $\begin{array}{c}* * \Delta \mathbf{H}_{\mathrm{m} 2} \\
(\mathbf{J} / \mathrm{g})\end{array}$ \\
\hline \multirow{2}{*}{$100 / 0$} & \multirow{2}{*}{2.6} & \multirow{2}{*}{------- } & \multirow{2}{*}{------- } & 163.2 & \multirow{2}{*}{89.62} \\
\hline & & & & 172.2 & \\
\hline \multirow{2}{*}{$98 / 2$} & \multirow{2}{*}{ - } & \multirow{2}{*}{------- } & \multirow{2}{*}{-------- } & 163.1 & \multirow{2}{*}{83.52} \\
\hline & & & & 172.7 & \\
\hline \multirow{2}{*}{$95 / 5$} & \multirow{2}{*}{-} & \multirow{2}{*}{------- } & \multirow{2}{*}{------- } & 161.1 & \multirow{2}{*}{84.27} \\
\hline & & & & 171.3 & \\
\hline \multirow{2}{*}{$90 / 10$} & \multirow{2}{*}{ - } & \multirow{2}{*}{27.5} & \multirow{2}{*}{0.76} & 159.6 & \multirow{2}{*}{76.50} \\
\hline & & & & 170.4 & \\
\hline \multirow{2}{*}{$80 / 20$} & \multirow{2}{*}{ - } & \multirow{2}{*}{44.8} & \multirow{2}{*}{6.60} & 156.5 & \multirow{2}{*}{62.09} \\
\hline & & & & 168.8 & \\
\hline $50 / 50$ & - & 47.9 & 35.53 & 157.7 & 20.13 \\
\hline $20 / 80$ & - & 48.6 & 88.4 & 145.0 & 1.63 \\
\hline 0/100 & - & 49.1 & 170.8 & -------- & ------ \\
\hline
\end{tabular}

$\mathrm{T}_{\mathrm{m} 1}-$ melting temperature of PEG. $\mathrm{T}_{\mathrm{m} 2}-$ melting temperature of PHBV. * calculated in function of percentage of PEG in the blend. ** calculated in function of percentage of PHBV in the blend.

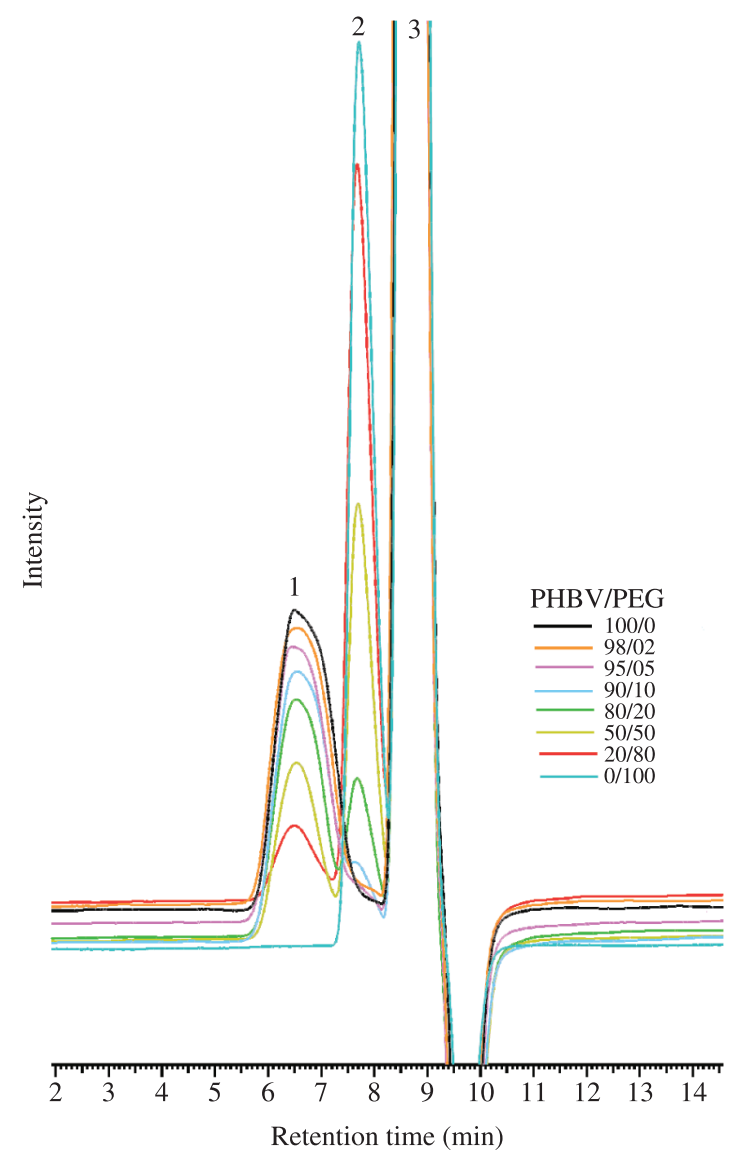

Figure 5. SEC of the PHBV/PEG mixtures. 


\section{Size exc/usion chromatography - SEC}

The SEC curves of PHBV/PEG mixtures are illustrated in Figure 5. O PHBV showed $M_{w}=206000$, while the PEG has $\mathrm{M}_{\mathrm{w}}=1350-1650$ (Cromato Chemicals). PHBV and PEG showed one peak, respectively. Nevertheless, PHBV/PEG mixtures showed two well-resolved elution peaks, respectively. One peak with much longer elution time was assigned to the PEG, another elution peak with less elution time was assigned to the PHBV which has higher molecular weight in comparison with original PEG. It is observed that the peak of PHBV decreases in intensity with increasing content of PEG in the sample, and lower molar masses, ie with higher content of PEG showed higher peaks due to the retention time of the sample is larger.

\section{Conclusions}

All samples exhibited a high crystallinity degree determined by XRD, due to the high crystallinity of PEG. The mixtures were uniform, except the 50/50 composition showed that presence of two phases. The SEC indicated that the mixtures have lower molar masses than the pure PHBV.

\section{Aknowledgements}

We thank Udesc for SEM and X-ray analysis and also CNPq for scholarship granted to master student Sara Elisa Moreira Catoni.

\section{References}

1. Mazur, L. P.; Da Silva, D. D.; Grigull, V. H.; Garcia, M. C. F.; Magalhães, T. O.; Wagner, T. M.; Einloft, S.; Dullius, J.; Schneider, A. L. \& Pezzin, A. P. T. - Mater. Sci. Eng. C. Biomin. Mater., Sens. Syst., 29, p.583 (2009).

2. Byrom, D. - Trends Biothecnol., 5, p.246 (1987). http:// dx.doi.org/10.1016/0167-7799(87)90100-4

3. Astar, J. \& Gruys, K. J. - "Biodegradable polymer: Biopol $^{\circledR}$ ", in: Steinbüchel, A \& Doi, Y. Biopolymers, v.4, WILEY-VCH, Weinheim 2002.

4. Wessler, K. - "Sistemas de $\mathrm{P}(3 \mathrm{HB})$ e $\mathrm{P}(3 \mathrm{HB}-\mathrm{co}-3 \mathrm{HV})$ com PCL-T: comportamento de fase, reologia, propriedades mecânicas e processabilidade", Dissertação de Mestrado, Universidade do Estado de Santa Catarina, Joinville (2007).

5. Moghimi S. M. \& Hunter A. C. - Crit. Rev. Ther. Drug, 18 p.527 (2001).

6. Parra, D. F.; Fusaro, J.; Gaboardi, F.\& Rosa, D. S. Polym. Degrad. Stab., 91, p.1954 (2006). http://dx.doi. org/10.1016/j.polymdegradstab.2006.02.008

7. Li, S.; Garreau, H.; Pauvert, B.; McGrath, J.; Toniolo, A. \& Vert, M. - Biomacromolecules, 3, p.525 (2002). http:// dx.doi.org/10.1021/bm010168s

8. Liu, Q. S.; Zhu, M. F.; Wu, W. H. \& Qin, Z. Y. - Polym. Degrad. Stab., 94, p.18 (2009). http://dx.doi.org/10.1016/j. polymdegradstab.2008.10.016

9. Brydson, J. A. - "Plastics Materials", 7.ed., Oxford, Butterworth Heinemann (2000).

Received: $30 / 08 / 11$

Revised: 22/11/12

Accepted: 13/12/12 